\title{
PEMBARUAN PENDIDIKAN ISLAM AZYUMARDI AZRA: Melacak Latar Belakang Argumentasinya
}

\author{
Hastuti Baharuddin \\ Pascasarjana UIN Alauddin Makassar \\ Jalan Sultan Alauddin Nomor 63 Makassar \\ Email: hastuti.baharuddin@yahoo.com
}

\begin{abstract}
Abstrak:
Pembaruan adalah proses atau cara membarui yang menghasilkan perubahan dalam penyesuaian situasi dan kondisi. Pendidikan Islam adalah proses mempersiapkan generasi muda (pembentukan individu) untuk menjalankan kehidupan (sebagai khalifah) dan untuk memenuhi tujuan hidup secara efektif dan efisien berdasarkan sumber-sumber Islam berupa al-Qura'n, sunnah, dan ijtihad. Pembaruan pendidikan Islam merupakan tuntutan kebutuhan dunia pendidikan Islam saat ini. Melihat ketertinggalan dan keterbelakangan umat Islam dewasa ini, maka inti dari pembaruan pendidikan Islam adalah berupaya meninggalkan pola pikir lama yang tidak sesuai dengan kemajuan zaman (future oriented) dan berupaya meraih aspek-aspek yang menopang untuk menyesuaikan diri dengan kemajuan zaman. Pendidikan Islam yang sebenarnya adalah balanced between worldly life and hereafter (keseimbangan antara dunia dan akhirat), balanced between revealed knowledge and acquired knowledge (keseimbangan antara pengetahuan wahyu dan pengetahuan usaha manusia), balanced between iman-taqwa and science and technology (keseimbangan antara imtak dan iptek) sehingga menghasilkan kesejahteraan spiritual dan material.
\end{abstract}

\begin{abstract}
Renewal is a process or a way of renewing the adjustment results in a change in circumstances. Islamic education is the process of preparing the younger generation (generation people) to run life (as Caliph) and to meet life goals effectively and efficiently based on the Islamic sources, the Qur'an, the sunnah, and ijtihad. Renewal of Islamic education is a demand to the needs of Islamic education in this time. Seeing underdevelopment and backwardness of Muslims today is that the core of the reform of Islamic education is attempting to leave the old mindset that is not in accordance with the progress of time (future oriented) and strive for sustaining aspects to conform with the progress of time. Islamic education is actually is balanced between worldly life and hereafter, balanced between revealed knowledge and acquired knowledge, balanced between iman-taqwa and science and technology so that resulting spiritual well-being and material well-being.
\end{abstract}

\section{Kata Kunci:}

Pembaruan, Pendidikan Islam, Globalisasi

BERAWAL pada abad ke-20 hingga saat kini, pendidikan Islam dalam tataran teoretik-konseptual boleh dikatakan mengalami kemandekan (stagnation) akut akibat kuatnya pengaruh sistem pendidikan tradisional. Selain itu, pendidikan Islam juga masih bercorak teologis-normatif tanpa memikirkan kontekstualnya. Akibatnya, pendidikan Islam sering terlambat merumuskan diri untuk merespons perubahan dan ke- 
cenderungan masyarakat sekarang dan akan datang. Pendidikan Islam tetap berorientasi pada masa silam ketimbang berorientasi masa depan, atau kurang bersifat future oriented. Selain itu, pendidikan Islam sering kalah bersaing dalam banyak segi dengan pendidikan umum. Bahkan, bukan rahasia lagi bahwa citra dan gengsi lembaga pendidikan Islam sering dipandang lebih rendah dibandingkan sistem pendidikan yang diselenggarakan pihak agama lain. Hal ini sangat dirasakan oleh beberapa kelompok umat Islam.

Kegalauan di atas memunculkan berbagai gagasan dan pemikiran para tokoh pendidikan mengenai pembaruan pendidikan Islam untuk menghadirkan pendidikan Islam yang mampu menjawab tantangan globalisasi. Salah satu tokoh yang masyhur di era ini adalah Azyumardi Azra (Rektor UIN Syarif Hidayatullah (1998-2006). Melihat ketertinggalan pendidikan Islam yang jauh terbelakang dari pendidikan umum, ia kemudian memunculkan gagasannya dalam bentuk modernisasi dan demokratisasi pendidikan Islam. Selain gagasan, Azyumardi Azra juga menyumbangkan pemikirannya terhadap restrukturisasi pendidikan Islam dalam kurikulum pendidikan Islam yang memuat perbaikan sumber, materi, metode, tenaga pendidik, evaluasi, karakteristik, lembaga, sarana, dan prasarana pendidikan Islam.

Berdasarkan uraian tersebut, tulisan ini mencoba melacak latar belakang yang menjadi penyebab munculnya ide/gagasan dan pemikiran Azyumardi Azra yang berujung pada pembaruan pendidikan Islam. Setelah mengevaluasi berbagai masalah dalam sistem pendidikan Islam, Azyumardi Azra kemudian mengimplementasikan gagasan dan pemikirannya pada perubahan IAIN menjadi UIN yang sudah terbukti sekarang ini bahwa UIN menjadi prototype bagi perguruan tinggi Islam lain.

Dalam pembahasan selanjutnya akan dikemukakan: pertama, latar belakang munculnya gagasan dan pemikiran Azyumardi Azra yang mendorong dilakukannya pembaruan pendidikan Islam, dan kedua, arah pembaruan pendidikan Islam Azyumardi Azra dalam bentuk gagasan dan pemikiran.

\section{PEMBAHASAN}

\section{Arah Pembaruan Pendidikan Islam Azyumardi Azra dalam Bentuk Gagasan dan Pemikiran}

Pendidikan Islam merupakan sebuah proses yang berlangsung cepat dan dinamis, bahkan merupakan yang paling banyak menghadapi masalah. Pelbagai aspek yang terkait dengan kegiatan pendidikan Islam, mulai dari dasar dan landasan pendidikan, kurikulum, tenaga pendidikan, metodologi pembelajaran, sarana dan prasarana, lembaga pendidikan, hingga pendanaan secara keseluruhan mengandung permasalahan yang sampai saat ini belum menemui penyelesaian komprehensif.

Berbagai masalah dalam pendidikan Islam terjadi disebabkan oleh eksternal and internal background. Yang dimaksud dengan eksternal background adalah pengalaman historis, tepatnya "warisan" penjajahan kolonialisme Barat terhadap dunia Islam abad ke-19 sampai abad ke-20, dan adanya proses pengkristenan orang Islam (kristenisasi). Adapun internal background terkait dengan ajaran Islam yang dinamis, yang 
bersumber dari al-Qur'an, sunnah, dan ijtihad, dan pengaruh konteks sosial-budaya masyarakat Indonesia.

Pembaruan pendidikan merupakan suatu keharusan karena faktor sosial-budaya masyarakat selalu mengalami perubahan, terutama disebabkan oleh perkembangan teknologi informasi yang kian cepat. Gagasan dan pemikiran Azyumardi Azra tentang pendidikan Islam sangat relevan dengan kondisi masyarakat zaman modern, sehingga patut dijadikan acuan dalam pelaksanaan pendidikan Islam, terutama di Indonesia.

Azyumardi Azra mengemukakan gagasannya mengenai modernisasi dan demokratisasi pendidikan Islam yang dihubungkan dengan tantangan abad 20 dan era globalisasi kemajuan sains dan teknologi. Demikian pula pemikirannya mengenai perlunya reformulasi dalam kurikulum pendidikan Islam. Menurutya, jika kaum muslimin termasuk Indonesia tidak hanya ingin survive di tengah persaingan global yang semakin tajam dan ketat, tetapi juga berharap mampu tampil ke depan. Reorientasi pemikiran mengenai pendidikan Islam dan restrukturisasi sistem dan kelembagaan, jelas merupakan kebutuhan. Cara pandang yang menganaktirikan sains dan teknologi tidak bisa lagi dipertahankan.

Pemikiran dan gagasan yang dikemukakannya didasarkan pada ajaran Islam yang pada prinsipnya kontekstual sesuai perkembangan zaman. Untuk itu, Azyumardi Azra mengatakan, pengamalan ilmu pengetahuan atas dasar tanggung jawab kepada Tuhan dan masyarakat manusia merupakan karakteristik pendidikan Islam. Pengetahuan bukan hanya untuk diketahui dan dikembangkan melainkan sekaligus dipraktekkan dalam kehidupan nyata.

Arah pemikiran Azyumardi Azra di atas bila ditarik ke perbendaharaan sejarah peradaban muslim dunia memiliki relevansi yang tinggi. Bahkan, penarikan sejarah itu bisa dilakukan hingga ke abad $14 \mathrm{M}$.

\section{Latar Belakang Munculnya Gagasan dan Pemikiran Azyumardi Azra tentang Pem- baruan Pendidikan Islam}

Sejarah mencatat pemekaran kebudayaan Islam terhenti pada akhir abad ke-14 M, yang ditandai dengan jatuhnya Spanyol. Mulai abad ke-15 M, dunia Islam satu per satu jatuh ke pangkuan kolonialisme-imperialisme Barat. Dalam era kolonialisme ini, kebudayaan Islam berjumpa lagi dengan kebudayaan Barat dalam bentuk yang terbalik. Secara kultural-institusional dan scientifik-teknologis, kebudayaan Barat telah jauh melampaui kebudayaan dan peradaban Islam. ${ }^{1}$

Kelemahan dan kemunduran umat Islam pada periode ini menjadikan adanya kontak langsung dengan dunia Barat. Kontak ini membuat para pemimpin Islam menyadari dan mengadakan perbandingan antara dunia Islam yang sedang menurun dan dunia Barat yang sedang menaik. Kesadaran bertambah lagi setelah beberapa negara Islam dapat ditundukkan Barat ke bawah kekuasaan mereka. ${ }^{2}$ Di antaranya, kejatuhan Mesir ke tangan Barat yang menginsafkan dunia Islam akan kelemahannya dan menyadarkan umat Islam bahwa di Barat telah timbul peradaban baru yang lebih tinggi dan merupakan ancaman bagi Islam. Dengan begitu, pada abad ke-18 dan ke- 
19 mulailah raja-raja dan pemuka-pemuka Islam memikirkan bagaimana meningkatkan mutu dan kekuatan umat Islam kembali. Periode inilah yang disebut periode modern ditandai timbulnya ide-ide pembaruan dalam Islam. ${ }^{3}$ Pembaruan tidak hanya terjadi dalam ranah politik kekuasaan, ekonomi, dan peradaban Islam, melainkan juga pembaruan yang paling penting terjadi pada sektor pendidikan.

Pada permulaan abad ke-19, kemajuan sains dan teknologi modern memasuki dunia Islam. Kontak dengan dunia Barat yang selanjutnya membawa ide-ide baru ke dunia Islam pada akhirnya menimbulkan persoalan-persoalan baru. ${ }^{4} \mathrm{Hal}$ ini dipertegas oleh William Montgomery Watt bahwa:

In education the loss of power by the ulema has been spectacular. All Islamic countries have a Western-type educational system up to university level, and it is this that most of the best brains of the country receive their education. This is absolutely necessary if the coutries are to function in the modern world with a reasonable degree of efficiency. One result of this process has been the creation of a new class of Western-educated people, most of whom do not accept the traditional Islamic world-view. These people are aware that the country cannot be run without them, and sometimes feel that they have an inadequated say in their country's future. The ulema have retained their traditional educational system, but it has shrunk in size and importance, since the great majority of children are in alternative system. ${ }^{5}$

Penegasan Montgomery di atas menunjukkan bahwa sistem pendidikan Islam telah bercampur dengan sistem pendidikan Barat. Ekspansi dunia Barat atas Timur tidak hanya terjadi dalam bidang ekonomi dan militer, tetapi juga ekspansi besar-besaran dalam bidang sosial, politik, ekonomi, pendidikan, dan sebagainya. Masa-masa ini yang disebut dengan masa kolonial dan imperial, yaitu masa di mana bangsabangsa Barat melakukan penjajahan atas dunia Timur, termasuk dunia muslim. Suasana seperti ini menyebabkan dunia Timur mengalami kemunduran dan Barat mencapai kemajuan pesat dari hasil kolonialisme dan imperialisme. ${ }^{6}$ Dukungan kemajuan teknologi memacu negara-negara Barat berlomba mencari daerah jajahan baru. Salah satu di antaranya penjajahan Belanda atas Indonesia.

Pada masa penjajahan, sekolah-sekolah Islam dikategorikan sebagai sekolah liar. Pemerintah kolonial memproduksi peraturan-peraturan yang membatasi dan mematikan sekolah-sekolah partikelir, termasuk pesantren, seperti peraturan Wilde Schoolen Ordonantie pada 1933.7 Hooker dalam Syamsul Kurniawan menulis bahwa pemerintah kolonial juga mengeluarkan peraturan yang dikenal dengan nama "ordonansi guru" (ordonansi 1905 dan 1925) yang menyebutkan bahwa izin tertulis untuk mengajar harus diberlakukan kepada Islam; bahwa daftar mata pelajaran dan peserta didik harus diketahui; dan bahwa metode pengawasan pemerintah juga harus dibuat. ${ }^{8}$

Ordonansi itu secara khusus dimaksudkan untuk membatasi gerakan pendidik agama dan secara umum dimaksudkan untuk menghambat kemajuan Islam. Dengan kata lain, pemerintah kolonial bersikeras, melalui berbagai kebijakannya menolak peranan Islam dalam kehidupan publik. Akibat kebijakan diskriminatif tersebut, pendi- 
dikan Islam menghadapi kesulitan-kesulitan dan bahkan terisolasi dari arus modernisasi. ${ }^{9}$

Sebagai akibatnya, muncul berbagai problem dalam pendidikan Islam di antaranya: pertama, terjadi dikotomi pendidikan antara pendidikan umum dengan pendidikan agama. ${ }^{10}$ Isi atau muatan pendidikan cenderung berorientasi pada praktekpraktek ritual keagamaan dan kurang memerhatikan sains dan teknologi; isi pendidikan masih bercorak dualistis sehingga antara pengajaran ilmu keagamaan dengan ilmu umum terkesan terpisah.

Kedua, pendidikan Islam menjadi kaku bahkan terlambat dalam merespons perubahan dan kecenderungan perkembangan masyarakat. ${ }^{11}$ Ketiga, lembaga pendidikan seperti madrasah diasosiasikan milik rakyat pinggiran dan kampungan serta terbelakang. Seperti bersambut, lembaga pendidikan Islam biasanya memang berada di kawasan pinggiran, dengan kondisi masyarakat yang agraris dan merupakan kelompok masyarakat ekonomi lemah. ${ }^{12}$

Keempat, pendidikan Islam mengalami persoalan manajemen, meskipun tidak seluruhnya bisa disebut negatif. Kelemahan manajemen ditunjukkan oleh sifatnya yang eksklusif dan tertutup dari dunia luar sehingga perkembangan pendidikan Islam pun menjadi lamban atau bahkan statis. ${ }^{13}$

Di samping masalah-masalah di atas, masih banyak lagi masalah yang menjadi penyebab kemunduran pendidikan Islam. di antaranya yang disebutkan oleh Jamaluddin al-Afghani bahwa kemuduran Islam bukanlah karena Islam dianggap tidak sesuai dengan perubahan zaman dan kondisi baru. Umat Islam mundur karena telah meninggalkan ajaran-ajaran Islam yang sebenarnya dan mengikuti ajaran-ajaran yang datang dari luar (asing bagi Islam). Sebab lain ialah salah memahami tentang maksud hadis yang mengatakan bahwa umat Islam akan mengalami kemunduran di akhir zaman. Salah pengertian ini membuat umat Islam tidak berusaha mengubah nasib mereka. ${ }^{14}$

Demikian pula pendapat Muhammad Abduh bahwa karena zaman dan suasana umat Islam sekarang telah jauh berubah dari zaman dan suasana umat Islam zaman klasik, ajaran-ajaran asli itu perlu disesuaikan dengan keadaan modern sekarang. Untuk menyesuaikan dengan situasi modern perlu diadakan interpretasi baru dan untuk itu, pintu ijtihad perlu dibuka. Dengan sendirinya, taklid tidak perlu dipertahankan bahkan harus diperangi karena taklid yang membuat umat Islam berada dalam kemunduran dan tidak dapat maju. Menurutnya; sikap ulama yang menimbulkan paham taklid membuat umat Islam berhenti berpikir dan akal mereka berkarat. ${ }^{15}$

Pemikir lain adalah Fazlur Rahman. Menurutnya, problem utama pendidikan Islam adalah problem ideologis, dualisme sistem pendidikan, bahasa, dan problem metode pembelajaran. ${ }^{16}$ Secara ideologis masyarakat tidak mengaitkan pentingnya pengetahuan dengan orientasi ajaran Islam. Problem kedua bahwa dikotomi dalam sistem pendidikan menjadikan sekolah Islam sulit menentukan kurikulum dengan keseimbangan ilmu agama dan ilmu pengetahuan lainnya. Problem bahasa yang di- 
maksud adalah Arab sentries yang tidak memadai membangun konsep-konsep bermutu yang modern. Problem terakhir bahwa Islam masih menggunakan paradigma pra-modern dalam menghadapi era modern.

Pendidikan Islam di era modern masih mengalami stganasi. Belum lagi jika mengungkit kelembagaan pendidikan Islam yang masih diragukan mampu menjawab tantangan zaman. Pendidik yang belum terlatih dan belum mampu berkompetisi secara masif. Terlebih lagi perilaku peserta didik yang sering bertentangan dengan tata nilai keislaman. Demikian pula mengenai prestasi peserta didik yang belum mampu diandalkan dalam bersaing di kancah dunia modern. Juga, dalam hal sumber belajar, strategi, metode, kurikulum, serta sarana dan prasarana yang masih lemah.

Berbagai permasalahan di atas menjadi kegalauan bersama bagi para pelaku pendidikan, sehingga muncullah sejumlah pemikir pembaruan pendidikan Islam. Dengan melihat realitas keterkungkungan pendidikan Islam dalam menjawab tantangan zaman modern, pembaruan memang harus dilakukan, agar pendidikan Islam bisa bangkit, maju, dan survive di era globalisasi ini. Dalam konteks sejarah inilah, arah pemikiran pembaruan pendidikan Islam oleh Azyumardi Azra bias diletakkan.

Era globalisasi dewasa ini sangat berpengaruh terhadap perkembangan sosial budaya masyarakat muslim Indonesia pada umumnya, atau pendidikan Islam pada khususnya. Argumen panjang lebar tidak perlu dikemukakan lagi bahwa masyarakat muslim tidak bisa menghindarkan diri dari arus globalisasi tersebut, apalagi jika ingin survive dan berjaya di tengah perkembangan dunia yang kian kompetitif. ${ }^{17}$

Fazlur Rahman mengemukakan bahwa pembaruan Islam dalam bentuk apapun yang berorientasi pada realisasi Islam yang asli dan modern harus bermula dari pendidikan. ${ }^{18}$ Dengan demikian, pendidikan Islam harus dijadikan sebagai salah satu tema sentral dari agenda rekonstruksi pemikiran ke depan. Sebab, ia merupakan "jantung" yang berdenyut memompakan spirit pembaruan ke seluruh bagian tubuh bangunan pemikiran Islam, agar mampu tumbuh dan berkembang secara dinamisprogresif. Dengan kata lain, kemajuan umat Islam akan sulit diwujudkan manakala tidak ditopang oleh kemajuan pendidikan.

Harus diakui bahwa hingga kini pendidikan Islam masih berada dalam posisi problematik. Di satu sisi, pendidikan Islam belum sepenuhnya bisa keluar dari idealisasi kejayaan pemikiran dan peradaban Islam masa lampau yang hegemonik; sementara di sisi lain, pendidikan Islam juga "dipaksa" untuk mau menerima tuntutan-tuntutan masa kini, khususnya yang datang dari Barat, dengan orientasi yang sangat praktis. Kenyataan tersebut acap kali menimbulkan dualisme dan polarisasi sistem pendidikan. ${ }^{19}$

Azyumardi Azra mengemukakan problematika pendidikan Islam sebagai berikut:

1. Pendidikan Islam sering terlambat merumuskan diri untuk merespons perubahan dan kecenderungan masyarakat sekarang dan akan datang.

2. Sistem pendidikan Islam kebanyakan masih cenderung mengorientasikan diri di bidang-bidang humaniora dan ilmu sosial dibanding ilmu eksakta. 
3. Usaha pembaruan pendidikan Islam sering bersifat sepotong-sepotong dan tidak komprehensif sehingga tidak terjadi perubahan yang esensial.

4. Pendidikan Islam tetap berorientasi pada masa silam ketimbang berorientasi masa depan, atau kurang bersifat future oriented.

5. Sebagian pendidikan Islam belum dikelola secara profesional, baik dalam tenaga pengajar, kurikulum maupun pelaksana pendidikannya. ${ }^{20}$

Kenyataan yang demikian, menurut Azyumardi Azra perlu segera dicarikan solusinya. Jika tidak segera diatasi, sulit diharapkan sistem dan lembaga pendidikan Islam bisa benar-benar fungsional dalam ikhtiar penyiapan sumber daya manusia (SDM) berkualitas tinggi dan kompetitif untuk menjawab tantangan zaman. ${ }^{21}$ Sehingga menurutnya, harus segera dilakukan pembaruan dalam sistem pendidikan Islam.

Menurut Azyumardi Azra perlu dikembangkan strategi pendekatan ganda dengan tujuan untuk memadukan sejumlah pendekatan situasional jangka pendek dengan pendekatan konseptual jangka panjang. Sebab, pendidikan Islam adalah suatu usaha mempersiapkan muslim agar dapat menghadapi dan menjawab tuntutan kehidupan dan perkembangan zaman secara manusiawi. Hubungan usaha pedidikan Islam dengan kehidupan dan tantangan itu haruslah merupakan hubungan yang parsial dan bukan hubungan insidental dan tidak menyeluruh. ${ }^{22}$ Di sinilah letak pentingnya sebuah upaya pembenahan dalam sistem pendidikan.

Di sisi lain, Azyumardi Azra juga mengajukan gagasan modernisasi pendidikan Islam. Asumsinya mempertahankan pemikiran kelembagaan Islam "tradisional" hanya akan memperpanjang nestapa kaum muslimin terhadap ketidakberdayaannya dalam berhadapan dengan kemajuan dunia modern. ${ }^{23}$ Ini berarti, sistem pendidikan Islam harus dapat memberikan disiplin keilmuan yang dapat membantu para lulusannya untuk dapat hidup di masyarakat secara layak. Diharapkan para lulusan yang diciptakan dapat berperan aktif dan bersikap opensif terhadap dinamika dan perubahan zaman.

Indonesia merupakan komunitas masyarakat muslim terbesardi dunia. Pendidikan Islam mestinya berperan lebih besar dalam kemajuan dunia pendidikan bangsa ini. Namun, kenyataanya pendidikan Islam di Indonesia masih menghadapi berbagai masalah dalam berbagai aspek. Lembaga-lembaga pendidikan Islam belum menemukan bentuk idealnya yang mampu mengembangkan potensi umat Islam dalam mengejar ketertinggalannya dari Barat modern. Oleh karena itu, setiap upaya ke arah pencarian sistem pendidikan yang merespons tuntutan masyarakat dan umat Islam perlu didukung. Inilah yang menjadi masalah pokok karena gagasan dan pemikiran Azyumardi Azra dalam pembaruan pendidikan Islam belum sepenuhnya diketahui masyarakat Indonesia sendiri.

Azyumardi Azra adalah salah satu tokoh dalam dunia pendidikan Indonesia yang banyak mengungkap permasalahan pendidikan Islam. Dia pernah menjabat rektor IAIN Syarif Hidayatullah antara tahun 1998-2002 kemudian UIN Syarif Hidayatullah pada tahun 2002-2006. Dia adalah tokoh pemikir yang karya-karyanya banyak dipublikasikan, baik dalam bentuk tulisan maupun sebagai pembicara di berba- 
gai media. Obsesinya yang besar untuk mengubah pemikiran Islam Indonesia menyebabkan dia dianggap sebagai salah satu tokoh pembaruan pendidikan Islam Indonesia di era modern ini.

\section{SIMPULAN}

Pendidikan Islam di era modern ini masih terasa masih tertinggal. Pendidikan Islam kalah bersaing dalam banyak segi dengan subsistem pendidikan lain dan sering dipandang lebih rendah dibandingkan dengan sistem pendidikan lainnya. Secara kelembagaan, pendidikan Islam masih diragukan kemampuannya untuk menjawab tantangan zaman, pendidik yang belum profesional dan lemah dalam berkompetisi secara massif. Perilaku peserta didik juga masih sering bertentangan dengan tata nilai keislaman, prestasi belajar yang belum siap bersiang dalam dunia modern. Demikian pula dalam hal sumber belajar, strategi, metode, kurikulum, serta sarana dan prasarana yang belum memadai. Berbagai hal inilah yang menjadi masalah dalam dunia pendidikan Islam di zaman globalisasi ini.

Azyumardi Azra sebagai tokoh yang sangat perhatian terhadap kegalauan tersebut melahirkan gagasan dan pemikirannya terkait pembaruan pendidikan Islam. Masuknya gagasan dan pembaruan pemikiran Azyumardi Azra sangat besar pengaruhnya bagi terealisasinya pembaruan pendidikan Islam. Upaya pembaruan pendidikan Islam yang dilakukan Azyumardi Azra dapat diartikan sebagai segala upaya untuk menata kembali struktur-struktur pendidikan Islam yang belum mapan dan ketinggalan zaman (out dated). Upaya untuk dalam merekonstruksi sistem pendidikan Islam agar menghasilkan perubahan signifikan dibanding dengan pendidikan Islam sebelumnya. Pembaruannya dalam gagasan adalah modernisasi dan demokratisasi pendidikan Islam dan atau gerakan berbentuk restrukturisasi kurikulum pendidikan Islam.

\section{CATATAN AKHIR}

1. M. Amin Abdullah, Islamic Studies di Perguruan Tinggi: Pendekatan Integratif-Interkonektif. Yogyakarta: Pustaka Pelajar, 2006, h. 248.

2. Harun Nasution, Pembaharuan dalam Islam: Sejarah Pemikiran dan Gerakan. Jakarta: Bulan Bintang, 1992, h. 206.

3. Ibid., h. 14.

4. Ibid., h. 11 .

5. W. Montgomery Watt, Islamic Fundamentalism and Modernity. New York: Routledge, 1988, h. $42-43$.

6. Murodi, Sejarah Kebudayaan Islam. Semarang: Karya Toha Putra, 1997, h. 149.

7. H. A. R. Tilaar, Paradigma Baru Pendidikan Nasional. Jakarta: Rineka Cipta, 2000, h. 169.

8. Syamsul Kurniawan, Pendidikan di Mata Soekarno: Modernisasi Pendidikan Islam dalam Pemikiran Soekarno. Yogyakarta: Ar-Ruzz Media Group, 2009, h. 21.

9. H. A. R. Tilaar, op. cit.,, h. 169-170.

10. Muljono Damopolii, "Potret Pendidikan Islam: Perspektif Pembaruan Pemikiran dan Gerakan Islam Indonesia Kontemporer", Lentera Pendidikan. Edisi X, No. 1, Juni 2007, h. 53. 
11. Azyumardi Azra, Pendidikan Islam: Tradisi dan Modernisasi di Tengah Tantangan Milenium III. Jakarta: Kencana Prenada Media Group, 2012, h. 66.

12. Syamsul Kurniawan, op. cit., h. 22.

13. Mahmud Arif, Pendidikan Islam Transformatif. Yogyakarta: LKiS Pelangi Aksara Yogyakarta, 2008, h. 203.

14. Harun Nasution, op. cit., h. 54-55.

15. Harun Nasution, op. cit., h. 64.

16. Abuddin Nata, Pemikiran Pendidikan Islam dan Barat. Cet. I; Jakarta: RajaGrafindo Persada, 2012, h. 322.

17. Azyumardi Azra, Pendidikan Islam: Tradisi dan Modernisasi Menuju Milenium Baru. Jakarta: Logos Wacana Ilmu, 2002, h. 43.

18. Fazlur Rahman, Islam. Bandung: Pustaka, 1997, h. 84.

19. Mahmud Arif, op.cit., h. 6-7.

20. Azyumardi Azra, Pendidikan Islam: Tradisi dan Modernisasi Menuju Milenium Baru, h. 85.

21. Ibid., h. 68 .

22. Azyumardi Azra, Esei-esei Intelektual Muslim dan Pendidikan Islam. Jakarta: Logos Wacana Ilmu, 1998, h. 23.

23. Azyumardi Azra, Pendidikan Islam: Tradisi dan Modernisasi Menuju Milenium Baru, op. cit., $\mathrm{h}$. 31.

\section{DAFTAR PUSTAKA}

Abdullah, M. Amin. Islamic Studies di Perguruan Tinggi: Pendekatan Integratif-Interkonektif. Yogyakarta: Pustaka Pelajar, 2006.

Arif, Mahmud. Pendidikan Islam Transformatif. Yogyakarta: LKiS Pelangi Aksara Yogyakarta, 2008.

Azra, Azyumardi. Jaringan Ulama Timur Tengah dan Kepulauan Nusantara Abad XVII dan XVIII: Melacak Akar-akar Pembaruan Pemikiran Islam di Indonesia. Bandung: Mizan, 1998.

-------. Esei-esei Intelektual Muslim dan Pendidikan Islam. Jakarta: Logos Wacana Ilmu, 1998.

-------. Pendidikan Islam: Tradisi dan Modernisasi Menuju Milenium Baru. Jakarta: Logos Wacana Ilmu, 1999.

------. Pendidikan Islam: Tradisi dan Modernisasi Menuju Milenium Baru. 2002.

------. Pendidikan Islam: Tradisi dan Modernisasi di Tengah Tantangan Milenium III. Jakarta: Kencana Prenada Media Group, 2012.

Muljono Damopolii. Potret Pendidikan Islam: Perspektif Pembaruan Pemikiran dan Gerakan Islam Indonesia Kontemporer. Lentera Pendidikan. Edisi X, No. 1, Juni 2007.

Kurniawan, Syamsul. Pendidikan di Mata Soekarno: Modernisasi Pendidikan Islam dalam Pemikiran Soekarno. Yogyakarta: Ar-Ruzz Media Group, 2009.

Murodi. Sejarah Kebudayaan Islam. Semarang: Karya Toha Putra, 1997.

Nasution, Harun. Pembaharuan dalam Islam: Sejarah Pemikiran dan gerakan. Jakarta: Bulan Bintang, 1992.

Rahman, Fazlur. Islam. Bandung: Pustaka, 1997.

Tafsir, Ahmad. Filsafat Pendidikan Islami: Integrasi Jasmani, Rohani, dan Kalbu Memanusiakan Manusia. Bandung: Remaja Rosdakarya, 2010.

Tilaar, H. A. R. Paradigma Baru Pendidikan Nasional. Jakarta: Rineka Cipta, 2000.

Watt, W. Montgomery. Islamic Fundamentalism and Modernity. New York: Routledge, 1988. 